Revta brasil. Bot., São Paulo, V.23, n.4, p.459-468, dez. 2000

\title{
Efeitos da seca sazonal e disponibilidade de luz na sobrevivência e crescimento de Bowdichia virgilioides em duas fitofisionomias típicas dos cerrados do Brasil Central
}

\author{
MIEKO F. KANEGAE ${ }^{1}$, VÍVIAN DA S. BRAZ ${ }^{1}$ e AUGUSTO C. FRANCO ${ }^{1,2}$
}

(recebido em 10 de março de 2000; aceito em 13 de setembro de 2000)

\begin{abstract}
Effects of seasonal drought and light availability on growth and survival of Bowdichia virgilioides in two characteristic savanna physiognomies of Central Brazil). Bowdichia virgiliodes Kunth is a common legume tree in the savannas of Central Brazil. This study investigated the effects of shading and of seasonal variations of soil water on the establishment and development of $B$. virgilioides in the 'campo sujo', a grassland with scattered trees and shrubs, and the 'cerradão', a woodland with a well-developed arboreous canopy. Soil remained wet during most of the rainy season, but short dry spells affected soil water potential of the upper layers. The soil under 'campo sujo' vegetation dried faster in the dry season. A larger percentage of seedlings emerged in the 'campo sujo'. Most of the mortality occurred shortly after germination, still in the wet season. Seasonal drought was not an important mortality factor. The 'cerradão' was not a favourable environment for the development of B. virgiliodes. Few cerradão seedlings survived, and 15 -month-old plants reached only $3.8 \pm 0.7 \mathrm{~cm}$ (mean $\pm \mathrm{SD}$ ) of total stem length, whereas the 'campo sujo' plants reached $6.9 \pm 1.3 \mathrm{~cm}$. Canopy shading reduced the photosynthetic photon flux density (PFD) available for understory seedlings and may be a major constrain for seedling growth. Shading by the tree layer in the cerradão had a much higher impact on PFD interception. A horizontal leaf located $5 \mathrm{~cm}$ aboveground would potentially fix 30 to $60 \%$ less $\mathrm{CO}_{2}$ than a leaf beneath the grass canopy of a 'campo sujo' and 60 to $80 \%$ less $\mathrm{CO}_{2}$ than an unshaded leaf. Because the height of the herb layer was less than $50 \mathrm{~cm}$, shading decreased markedly with plant height in the 'campo sujo'.
\end{abstract}

RESUMO - (Efeitos da seca sazonal e disponibilidade de luz na sobrevivência e crescimento de Bowdichia virgilioides em duas fitofisionomias típicas dos cerrados do Brasil Central). Bowdichia virgilioides Kunth, uma leguminosa arbórea comum no cerrado, ocorre no campo sujo, em que predomina o estrato herbáceo e em formações florestais, como o cerradão. Neste estudo investigou-se os efeitos do sombreamento e da seca sazonal no estabelecimento e desenvolvimento dessa espécie nestas duas fitofisionomias. O solo permaneceu úmido durante a maior parte da estação chuvosa, mas curtos períodos sem chuva afetaram o potencial de água das camadas superficiais. Ao longo da estação seca, o solo sob campo sujo secou mais rapidamente. A emergência de plântulas foi maior no campo sujo e a maior parte da mortalidade ocorreu logo após a emergência, durante a estação chuvosa. A estação seca não foi um fator importante de mortalidade. O ambiente florestal não foi favorável ao desenvolvimento desta espécie. Poucas plantas sobreviveram no cerradão e atingiram apenas 3,8 $\pm 0,7 \mathrm{~cm}$ (média \pm desvio padrão) de comprimento da parte aérea, enquanto as plantas no campo sujo atingiram $6,9 \pm 1,3 \mathrm{~cm}, 15$ meses após a semeadura. O sombreamento pode ser um dos principais fatores que limitam o desenvolvimento inicial dessa espécie. Devido ao dossel arbóreo, os efeitos do sombreamento foram críticos no cerradão. A $5 \mathrm{~cm}$ acima do solo no cerradão, a densidade de fluxo de fótons na faixa fotossinteticamente ativa manteria taxas estimadas de assimilação de $\mathrm{CO}_{2}\left(\mathrm{ACO}_{\mathrm{CO}}\right)$ entre 40 e $70 \%$ da $\mathrm{A}_{\mathrm{CO} 2}$ para a mesma altura no campo sujo e entre 20 e $40 \%$ da $\mathrm{A}_{\mathrm{CO} 2}$ para uma superfície sem sombreamento. No campo sujo, à proporção que a planta cresce, o sombreamento diminuiria rapidamente, devido ao baixo porte do dossel herbáceo, que atingiu uma altura máxima de $50 \mathrm{~cm}$.

Key words - Light availability, microhabitats, neotropical savannas, soil water potential, seedlings

\section{Introdução}

O cerrado é a vegetação característica do Planalto Central do Brasil, apresentando fisionomias que englobam formações florestais, savânicas e campestres. Entre os seus principais tipos fitofisionômicos estão o cerradão e o campo sujo.

O cerradão é uma formação florestal com aspectos xeromórficos, caracterizando-se pela presença de

1. Departamento de Botânica, Universidade de Brasília, Caixa Postal 04457, 70919-970 Brasília, DF, Brasil.

2. Autor para correspondência: acfranco@unb.br espécies que ocorrem no cerrado sentido restrito e também por espécies de mata, com uma cobertura arbórea que pode oscilar entre 50 a 90\% (Ribeiro \& Walter 1998). A altura média do estrato arbóreo varia de 8 a $15 \mathrm{~m}$, proporcionando condições de luminosidade que favorecem a formação de estratos arbustivos e herbáceos diferenciados. De um modo geral, os cerradões estão associados a solos profundos, bem drenados, ácidos e de baixa fertilidade. $\mathrm{O}$ campo sujo é um tipo fisionômico predominantemente herbáceo-arbustivo, constituído por indivíduos menos desenvolvidos das espécies arbóreas do cerrado sentido restrito. Essa fitofisionomia é geral- 
mente encontrada em solos rasos ou em solos profundos de baixa fertilidade.

O clima do cerrado é caracterizado pela presença de uma estação seca de 4 a 6 meses de duração, que reduz a disponibilidade de água nas camadas superficiais do solo, enquanto as camadas mais profundas permanecem úmidas (Nardoto et al. 1998, Jackson et al. 1999). Plantas lenhosas, por apresentarem sistema radicular profundo, teriam acesso às reservas de água do subsolo, apesar de algumas espécies lenhosas do cerrado apresentarem um sistema radicular superficial (Rawitscher 1948, Jackson et al. 1999).

O déficit hídrico sazonal pode exercer um efeito mais marcado em plântulas e indivíduos jovens, cujos sistemas radiculares ficariam mais expostos à escassez de água nas camadas superficiais do solo, característico da época seca. O crescimento radicular rápido e o desenvolvimento de órgãos de reserva são algumas formas de garantir a sobrevivência na seca (Labouriau et al. 1963, Handro 1969). Entretanto, plântulas de Dalbergia miscolobium e Kielmeyera coriacea, duas espécies lenhosas típicas do cerrado, apresentaram alta mortalidade durante a estação chuvosa (Franco et al. 1996a).

Modelos para explicar o funcionamento de savanas neotropicais consideram as variações sazonais na disponibilidade de água como o principal fator limitante da produtividade vegetal e pressupõem que os elementos arbóreos são capazes de se estabelecer na matriz herbácea (Medina \& Silva 1990). Em uma área de campo sujo, em que predominava o estrato herbáceo, mudas de $K$. coriacea, se desenvolveram lentamente, não ultrapassando a média de $2,8 \mathrm{~cm}$ de altura, cerca de 29 meses após a germinação (Nardoto et al. 1998). Este crescimento lento da parte aérea também foi observado em muitas espécies em condições de viveiro (Rizzini 1965). Entretanto, não existem estudos comparando o crescimento de espécies lenhosas e as variações na disponibilidade de água e luz ao longo de um gradiente fisionômico de campo sujo a cerradão. Em ambientes mais abertos, a disponibilidade de luz talvez não afete o crescimento de indivíduos lenhosos em fase de estabelecimento, mas a medida que o dossel arbustivo-arbóreo se torna mais fechado, o sombreamento pode se tornar um fator crítico. Estes estudos são essenciais para a compreensão dos processos de coloni- zação e regeneração dos ecossistemas savânicos característicos do Brasil Central.

Bowdichia virgilioides Kunth (sucupira preta) é uma leguminosa arbórea comum nos cerrados do Planalto Central e em outras savanas da América do Sul, como os llanos venezuelanos (Sarmiento 1984). Em uma análise da composição florística de 98 áreas de cerrado e savana amazônica, englobando a maior parte desta vegetação no Brasil, B. virgilioides foi uma das espécies lenhosas de maior distribuição, tendo ocorrido em $76 \%$ das áreas amostradas (Ratter et al. 1996). Entretanto, não conhecemos estudos sobre a sobrevivência e desenvolvimento dessa espécie em condições naturais, nos cerrados do Planalto Central.

O objetivo desse estudo foi examinar as variações sazonais da água no solo e a disponibilidade de luz em duas fitofisionomias distintas, o campo sujo e o cerradão e seus efeitos no estabelecimento e desenvolvimento de $B$. virgilioides.

\section{Material e métodos}

Esse estudo foi conduzido na Fazenda Experimental da Universidade de Brasília (Fazenda Água Limpa - FAL), localizada a cerca de $20 \mathrm{~km}$ ao sul da cidade de Brasília $\left(15^{\circ} 56^{\prime} \mathrm{S}\right.$ e $47^{\circ} 55^{\prime} \mathrm{W}$ ). A última queimada na área de estudo ocorreu em 1991. De acordo com dados da estação meteorológica da Reserva Ecológica do IBGE ( $15^{\circ} 57^{\prime} \mathrm{S}$ e $\left.47^{\circ} 57^{\prime} \mathrm{W}\right)$, a precipitação média anual fica em torno de $1500 \mathrm{~mm}$, com uma estação seca bem definida de maio a setembro. Os solos da área de estudo são distróficos, com baixa fertilidade e praticamente não diferem em conteúdo nutricional entre as duas fitofisionomias (Haridasan 1987). Considerando-se todas as lenhosas que apresentaram um diâmetro de caule de pelo menos $5 \mathrm{~cm}$, a $30 \mathrm{~cm}$ de altura do solo, o campo sujo apresentou uma densidade de 533 indivíduos por hectare, enquanto o cerradão apresentou uma densidade de 2800 indivíduos por hectare.

Para determinar a disponibilidade de água no solo, o grau de sombreamento dos sítios experimentais e estimar os efeitos do sombreamento nas taxas de assimilação de $\mathrm{CO}_{2}$, seguiu-se o procedimento de Franco \& Nobel (1988), adaptado para as condições do cerrado por Nardoto et al. (1998). Desta maneira, o potencial de água do solo $(\Psi \mathrm{s})$ foi medido com psicrômetros de solo (Modelo PST-55-30 SF, Wescor Inc., Logan, Utah, E.U.A.) nas profundidades de $5,15,30,60$ e $85 \mathrm{~cm}$, sendo 5 psicrômetros instalados em cada profundidade. De uma maneira geral, $\Psi$ s foi medido a cada 10 dias.

O grau de sombreamento dos dois ambientes foi obtido utilizando-se fotodiodos instalados em duas hastes metálicas, a 5 , $10,15,20$ e $50 \mathrm{~cm}$ de altura, acoplados a um milivoltímetro. Os fotodiodos foram previamente calibrados em densidade de fluxo de fótons na faixa fotossinteticamente ativa (DFF; $\lambda=400$ $700 \mathrm{~nm}$ ) contra um sensor de quanta, da LICOR, E.U.A., modelo 
LI-190-S. Os 10 fotodiodos foram orientados paralelamente ao solo, medindo a DFF incidente em uma superfície horizontal. Medições do curso diário da DFF foram feitas em dias típicos da estação chuvosa (27 de dezembro 1995, 24 de março 1996, 20 de outubro 1996), sem modificar a vegetação local. No campo sujo, os dois fotodiodos a $50 \mathrm{~cm}$ de altura ficaram acima do dossel graminoso.

A assimilação líquida instantânea de $\mathrm{CO}_{2}\left(\mathrm{Aco}_{2}\right)$ em função do DFF foi estimada a partir da equação $\mathrm{AcO}_{2}=9,2 *\left(1-\mathrm{e}^{-0,0033^{*}(\mathrm{DFF}-21)}\right)$, obtida para B. virgilioides em condições naturais, na estação chuvosa (Prado 1994, Prado \& Moraes 1997). Baseado nesta equação, o valor máximo de assimilação de $\mathrm{CO}_{2}$ seria $9,2 \mu \mathrm{mol} . \mathrm{m}^{-2} . \mathrm{s}^{-1}$ para esta espécie em condições naturais. A partir das medidas instantâneas de DFF e utilizando-se esta equação, obteve-se uma estimativa de $\mathrm{Aco}_{2}$ para cada valor de DFF obtido ao longo do período luminoso.

Para examinar os efeitos do tipo de fitofisionomia no estabelecimento e desenvolvimento desta espécie, 75 sementes de $B$. virgiliodes foram plantadas em campo sujo e 65 em cerradão, em 4 de dezembro de 1997. Para facilitar a embebição, as sementes foram escarificadas mecanicamente. Com o objetivo de verificar a sua viabilidade, 18 sementes escarificadas do mesmo lote foram colocadas para germinar em placa de petri com papel de filtro, na bancada do laboratório, resultando em $72 \%$ de germinação. A temperatura do ar, irradiância e fotoperíodo do laboratório não foram controlados, mas valores típicos de temperatura estavam na faixa de $25{ }^{\circ} \mathrm{C}$ e a irradiancia logo acima das placas de petri foi de $1 \mathrm{~W} \mathrm{~m}^{-2}$. Como houve uma baixa sobrevivência das plântulas no cerradão, o procedimento de campo foi repetido em 29 de novembro de 1998, quando foram plantadas 156 sementes, sendo metade no campo sujo e o restante no cerradão. Neste caso, as sementes não foram escarificadas, pois experimento preliminar em bancada de laboratório com 19 sementes não escarificadas do mesmo lote, resultou em $100 \%$ de germinação. Nas condições de campo, as sementes foram colocadas em pequenas covas ( $1 \mathrm{a} 2 \mathrm{~cm}$ de profundidade), sendo cobertas com solo.

As medidas iniciais de crescimento e sobrevivência dessas plântulas foram feitas a cada dez dias no decorrer de dois meses, espaçando logo em seguida para uma vez por mês. O comprimento total da parte aérea e o número total de folíolos presentes em cada planta foram medidos mensalmente, sendo escolhidos como parâmetros de produtividade. Uma planta era considerada morta quando perdia todos os folíolos e não rebrotava. Para os cálculos de produtividade foram consideradas apenas as plantas que sobreviveram durante todo o período do estudo.

\section{Resultados}

Precipitação e potencial hídrico do solo - A distribuição das chuvas seguiu o padrão típico da região Centro-Oeste, com a maior parte da precipitação ocorrendo entre os meses de outubro a abril (figura 1). A estação seca se estendeu de maio a setembro de 1998, quando a precipitação mensal foi inferior a $5 \mathrm{~mm}$. O potencial de água do solo $(\Psi \mathrm{s})$ permaneceu próximo à capacidade de campo $(\Psi \mathrm{s}=-0,06 \mathrm{MPa})$ durante a estação chuvosa (figura 2). Veranicos (pe-

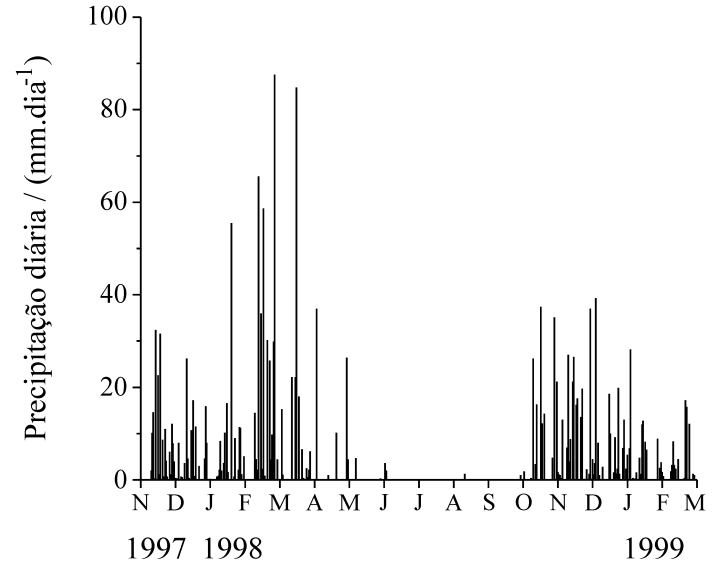

Figura 1. Precipitação diária para o período de 1 de novembro de 1997 a 28 de fevereiro de 1999. Dados fornecidos pela estação meteorológica da Reserva Ecológica do IBGE, DF.

ríodos sem precipitação durante a estação chuvosa) afetaram predominantemente $\mathrm{o} \Psi$ nas profundidades de 5 e $15 \mathrm{~cm}$. Em um veranico mais longo, registrado em janeiro de 1998, $\Psi$ s chegou a atingir -1,3 MPa no campo sujo e - $-0,8 \mathrm{MPa}$ no cerradão, a $5 \mathrm{~cm}$ de profundidade.

$\Psi$ s diminuiu consideravelmente durante a estação seca, atingindo um mínimo de $-6,2 \mathrm{MPa}$ a $5 \mathrm{~cm}$ de profundidade e $-2,6 \mathrm{MPa}$ a $60 \mathrm{~cm}$ de profundidade, no campo sujo. No cerradão, $\Psi$ s atingiu valores mínimos de -2,8 e -1,8 MPa, para estas mesmas profundidades.

Disponibilidade de luz e fotossíntese - A figura 3 representa a variação diária da DFF durante três dias típicos do início, meio e fim da estação chuvosa. Em 27 de dezembro de 1995, o dia permaneceu nublado e a DFF atingiu um máximo de $1042 \mu \mathrm{mol} \cdot \mathrm{m}^{-2} \cdot \mathrm{s}^{-1}$ no campo sujo a $50 \mathrm{~cm}$ de altura e $685 \mu \mathrm{mol} \cdot \mathrm{m}^{-2} . \mathrm{s}^{-1}$ no cerradão, por volta de $13 \mathrm{~h}$ (figuras 3C, D). $\mathrm{O}$ dia 24 de março de 1996 foi caracterizado pela presença de nuvens e chuva por volta do meio dia. A DFF apresentou grandes oscilações no campo sujo, chegando a atingir $2400 \mu \mathrm{mol} . \mathrm{m}^{-2} . \mathrm{s}^{-1}$ a $50 \mathrm{~cm}$ de altura e valores menores do que $200 \mu \mathrm{mol} \cdot \mathrm{m}^{-2} \cdot \mathrm{s}^{-1} \mathrm{em}$ todas as alturas a partir das $14 \mathrm{~h}$ e $30 \mathrm{~min}$. No cerradão, os valores de DFF a $50 \mathrm{~cm}$ de altura mantiveram-se abaixo de $800 \mu \mathrm{mol} . \mathrm{m}^{-2} . \mathrm{s}^{-1}$ ao longo do dia, permanecendo inferiores a $250 \mu \mathrm{mol} . \mathrm{m}^{-2} \cdot \mathrm{s}^{-1}$ nas 

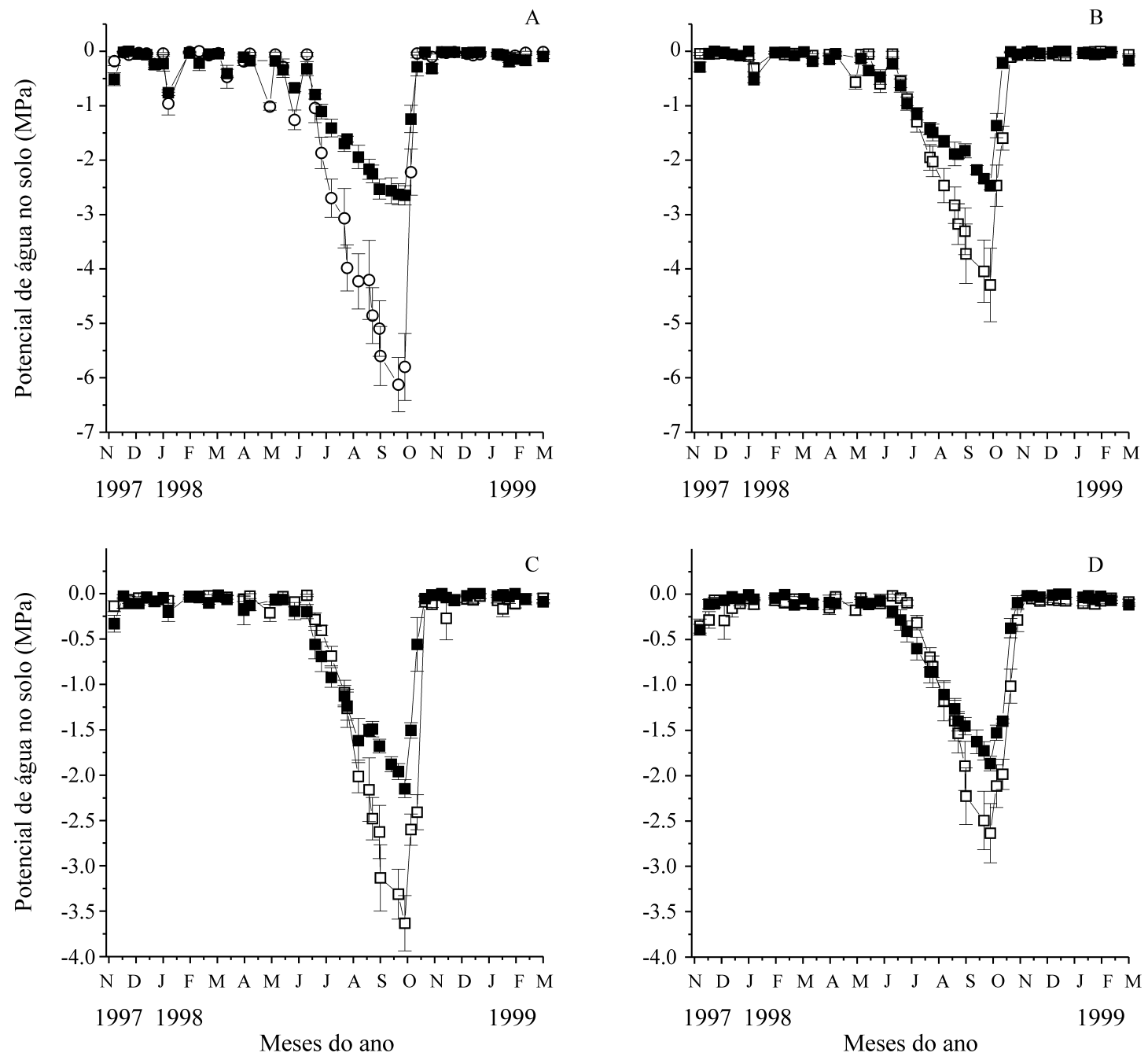

Figura 2. Variação sazonal do potencial de água do solo (média \pm erro padrão; $n=5$ ) a diferentes profundidades, no campo sujo e

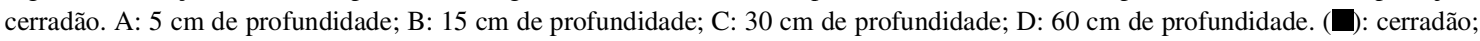
(O): campo sujo.

outras alturas. Em 20 de outubro de 1996, o dia permaneceu sem nuvens durante a manhã e a DFF ultrapassou $2000 \mu \mathrm{mol} \mathrm{m}^{-2} \mathrm{~s}^{-1}$ por volta do meio dia, a $50 \mathrm{~cm}$ de altura no campo sujo, mas permaneceu com valores inferiores a $1000 \mu \mathrm{mol} . \mathrm{m}^{-2} . \mathrm{s}^{-1}$ no cerradão. A ocorrência de nuvens na parte da tarde provocou uma redução substancial nos valores de DFF em ambos os ambientes.

No campo sujo, os efeitos do sombreamento diminuíram rapidamente com o aumento da distância entre o solo e o sensor de DFF, devido ao baixo porte do dossel herbáceo, que atingiu um máximo de $50 \mathrm{~cm}$ de altura. Folhas localizadas a esta altura não sofreriam sombreamento pelo dossel herbáceo. Este aumento na DFF incidente em função da altura do sensor em relação ao solo também ocorreu no cerradão, mas o dossel arbóreo continuou tendo um papel importante na interceptação da DFF incidente, mesmo a uma altura de $50 \mathrm{~cm}$ da superfície do solo. Desta maneira, uma superfície horizontal a $5 \mathrm{~cm}$ do solo, recebeu em média entre 30 a $55 \%$ da DFF que uma superfície na mesma altura recebeu no campo 

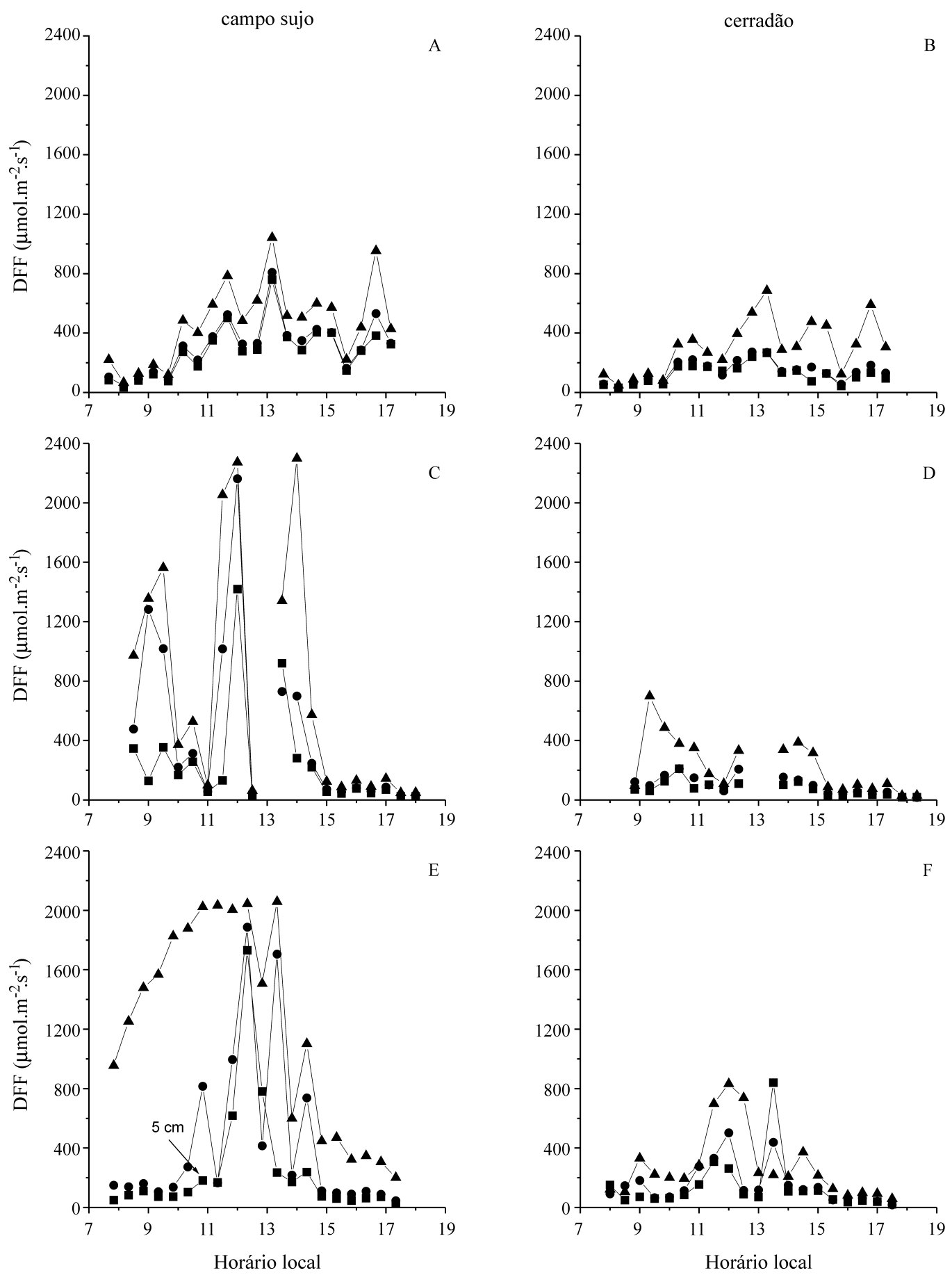

Figura 3. Variação na densidade de fluxo de fótons (DFF) a 5,10 e $50 \mathrm{~cm}$ de altura durante o período luminoso diário, no campo sujo e cerradão. A, B: 27 de dezembro de 1995; C, D: 24 de março de 1996; E, F: 20 de outubro de 1996. A interrupção das curvas em março de 1996 significa que a DFF não foi medida, devido à ocorrência de chuva no momento da medição. As medidas foram retomadas após a chuva. $(\mathbf{\Lambda}): 50 \mathrm{~cm} ;(\bullet): 10 \mathrm{~cm}$. 
sujo. Uma superfície a $50 \mathrm{~cm}$ de altura, recebeu entre 22 a $65 \%$ da DFF que atingiu a mesma altura no campo sujo.

O sombreamento limitaria as taxas de assimilação de $\mathrm{CO}_{2}\left(\mathrm{~A}_{\mathrm{CO} 2}\right)$ nos dois ambientes (tabela 1). Se considerarmos o valor de $9,2 \mu \mathrm{mol} . \mathrm{m}^{-2} . \mathrm{s}^{-1}$ como a capacidade fotossintética máxima para esta espécie (Prado 1994), somente folhas localizadas a mais de $50 \mathrm{~cm}$ de altura no campo sujo, apresentariam valores próximos ao máximo, em dias ensolarados. No cerradão, a DFF incidente a uma altura de $5 \mathrm{~cm}$ do solo, manteria taxas médias de $\mathrm{A}_{\mathrm{CO} 2}$ extremamente reduzidas para folhas localizadas a esta altura. Os valores ficariam entre 40 e $70 \%$ da $\mathrm{A}_{\mathrm{CO} 2}$, estimada para a mesma altura no campo sujo e entre 20 e $40 \%$ da $\mathrm{A}_{\mathrm{CO} 2}$, estimada para uma superfície sem sombreamento. Entretanto, à medida que aumentasse a distância entre as folhas e a superfície do solo, diminuiria o sombreamento, aumentando a disponibilidade de luz e a capacidade estimada da planta de assimilar $\mathrm{CO}_{2}$. Um aumento da distância entre superfície do solo e as folhas de 5 para $50 \mathrm{~cm}$ de altura, resultaria em um aumento de 1,3 a 2,7 vezes na assimilação estimada de $\mathrm{CO}_{2}$ (tabela 1).

Estabelecimento e crescimento de B. virgilioides Houve maior porcentagem de emergência e sobrevivência de plantas de $B$. virgiliodes no campo sujo do que no cerradão (figura 4). Para as sementes plantadas em 4 de dezembro de 1997, plântulas emergiram de $40 \%$ das sementes no campo sujo e de $32 \%$ das sementes no cerradão, sendo que a grande maioria destas surgiu nos primeiros dias após a semeadura. Destas plantas que emergiram, $67 \%$ permaneciam vivas em fevereiro de 1999 no campo sujo e $20 \%$ no cerradão. No segundo experimento, iniciado em 29 de novembro de 1998, plântulas emergiram de 60\% das sementes no campo sujo e de $19 \%$ das que foram semeadas no cerradão, em um período de 24 dias. A maioria (85\%) das plantas no campo sujo sobreviveu. No cerradão, apenas uma das 13 plantas que emergiram, permaneceu viva até fevereiro de 1999.

Os cotilédones também persistiram por mais tempo nas plântulas do campo sujo. Para as sementes plantadas em 4 de dezembro de 1997, 8 de 21 plântulas ainda apresentavam cotilédones no campo sujo em junho de 1998, enquanto no cerradão, apenas 1 em 7 manteve os cotilédones nesse mesmo período (figura 5). A ausência de cotilédones em 5 plântulas do cerradão já havia sido notada em maio de 1998.

As plantas cresceram e produziram folhas somente durante o período chuvoso. Durante a estação seca, ocorreu diminuição no número total de folíolos por planta e interrupção no crescimento da parte aérea. Para as plantas semeadas em 4 de dezembro de 1997, o número total de folíolos por planta diminuiu de 13,2 $\pm 3,4$ folíolos (média \pm desvio padrão; $\mathrm{n}=20$ plantas) para $10,5 \pm 1,0$ folíolos no campo sujo, entre o início (29 de maio de 1998) e o final (20 de setembro de 1998) da estação seca. O comprimento da parte aérea destas plantas mantevese estável; sendo 4,8 $\pm 1,1 \mathrm{~cm}$ em 29 de maio e 4,9 $\pm 0,3 \mathrm{~cm}$, em 20 de setembro de 1998 . No cerradão, o número de folíolos por planta diminuiu de 7,3 \pm 1,5 folíolos ( $\mathrm{n}=4$ plantas) para 4,8 $\pm 3,4$ folíolos, enquanto o comprimento da parte aérea não variou, passando de $2,7 \pm 0,2 \mathrm{~cm}$ para $2,8 \pm 0,7 \mathrm{~cm}$.

Tabela 1. Taxa média estimada da assimilação líquida de $\mathrm{CO}_{2}\left(\mu \mathrm{mol} \cdot \mathrm{m}^{-2} \cdot \mathrm{s}^{-1}\right.$; média \pm desvio padrão), baseada em medidas instantâneas de DFF obtidas a cada 30 minutos ao longo do período luminoso. A DFF foi medida em dias representativos do meio ( 27 de dezembro de 1995), final (24 de março de 1996) e início (20 de outubro de 1996) da estação chuvosa.

\begin{tabular}{lcccccc}
\hline \multirow{2}{*}{ Data } & Vegetação & \multicolumn{5}{c}{ Altura acima do solo } \\
\cline { 3 - 6 } & & $5 \mathrm{~cm}$ & $10 \mathrm{~cm}$ & $15 \mathrm{~cm}$ & $20 \mathrm{~cm}$ & $50 \mathrm{~cm}$ \\
\hline \multirow{2}{*}{27 dezembro de 1995 } & Campo sujo & $4,7 \pm 2,2$ & $5,1 \pm 2,2$ & $5,7 \pm 2,3$ & $5,8 \pm 2,2$ & $6,3 \pm 2,2$ \\
& Cerradão & $2,6 \pm 1,5$ & $3,0 \pm 1,6$ & $3,7 \pm 1,9$ & $4,1 \pm 1,9$ & $5,2 \pm 2,4$ \\
\multirow{2}{*}{24 março de 1996 } & Campo sujo & $2,8 \pm 2,9$ & $3,9 \pm 3,5$ & $4,4 \pm 3,5$ & $4,5 \pm 3,6$ & $5,2 \pm 3,5$ \\
& Cerradão & $1,2 \pm 1,3$ & $1,6 \pm 1,7$ & $2,3 \pm 2,2$ & $2,4 \pm 2,2$ & $3,3 \pm 2,8$ \\
20 outubro de 1996 & Campo sujo & $3,0 \pm 2,7$ & $4,3 \pm 2,8$ & $5,9 \pm 2,6$ & $6,4 \pm 2,4$ & $8,1 \pm 1,6$ \\
& Cerradão & $2,1 \pm 1,9$ & $2,7 \pm 2,1$ & $3,0 \pm 2,0$ & $3,1 \pm 2,0$ & $4,1 \pm 2,2$ \\
\hline
\end{tabular}



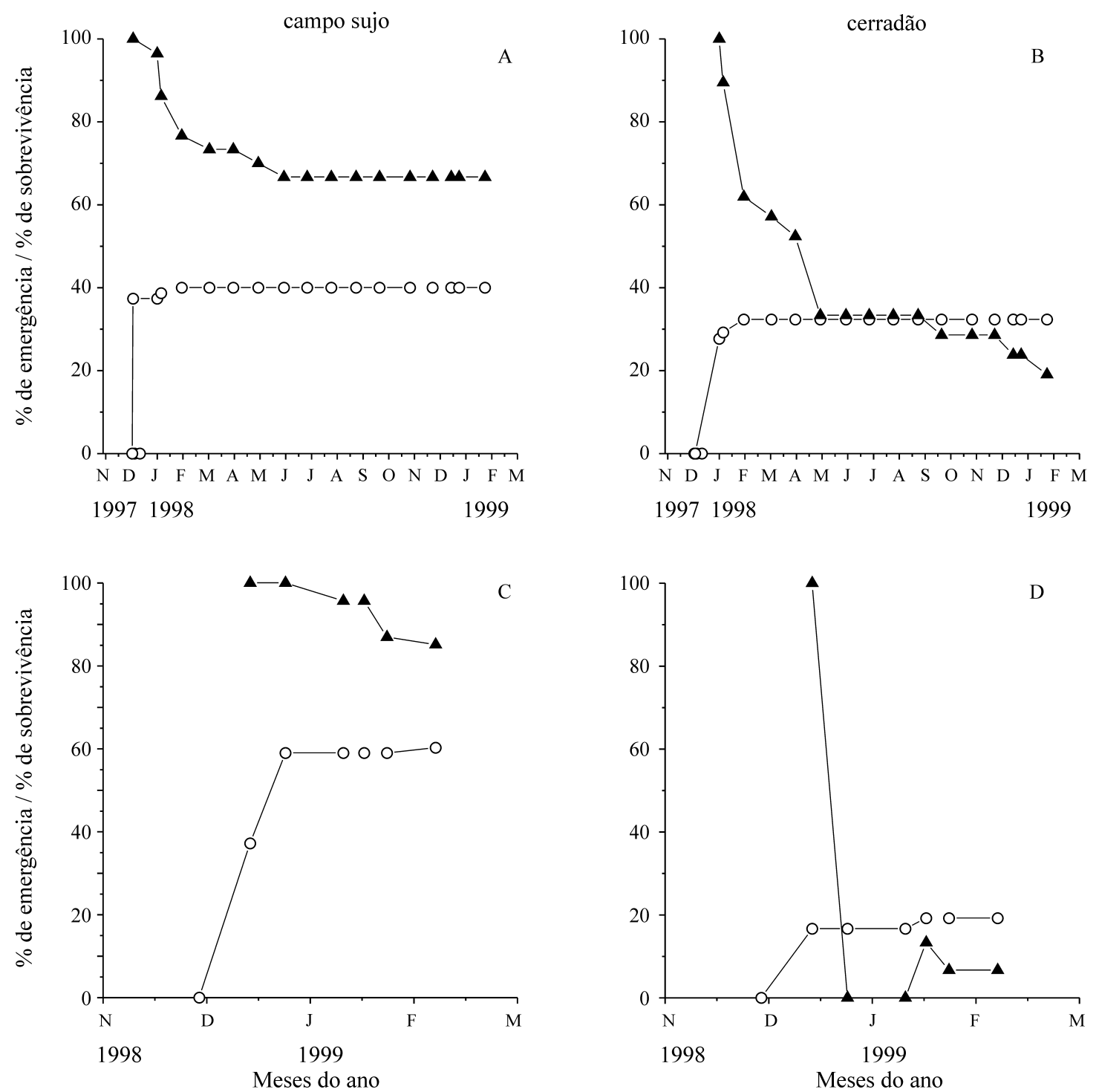

Figura 4. Porcentagem de emergência e sobrevivência das plântulas de Bowdichia virgilioides no campo sujo e no cerradão. As sementes foram semeadas nas duas fitofisionomias nos dias 4 de dezembro de 1997 (A, B) e 29 de novembro de 1998 (C, D). (A): sobrevivência; (O): emergência.

Em 28 de fevereiro de 1998, cerca de 15 meses após a semeadura, as plantas do campo sujo alcançaram $6,9 \pm 1,3 \mathrm{~cm}$ de comprimento e totalizavam 27,4 $\pm 9,7$ folíolos por planta. No cerradão, as plantas alcançaram somente $3,8 \pm 0,7 \mathrm{~cm}$ de comprimento e mantinham um total de 13,0 $\pm 2,7$ folíolos por planta. Essas diferenças entre as fitofisionomias foram estatisticamente significantes, tanto em relação ao comprimento (Teste $t ; t=6,81$, $\mathrm{P}=0,0002$ ), quanto em relação ao número de folíolos (Teste de Kruskal-Wallis; $\mathrm{P}=0,0017$ ).

\section{Discussão}

Os primeiros meses após a emergência das plântulas foram os mais críticos para o estabelecimento de B. virgilioides. A maior parte da mortalidade 


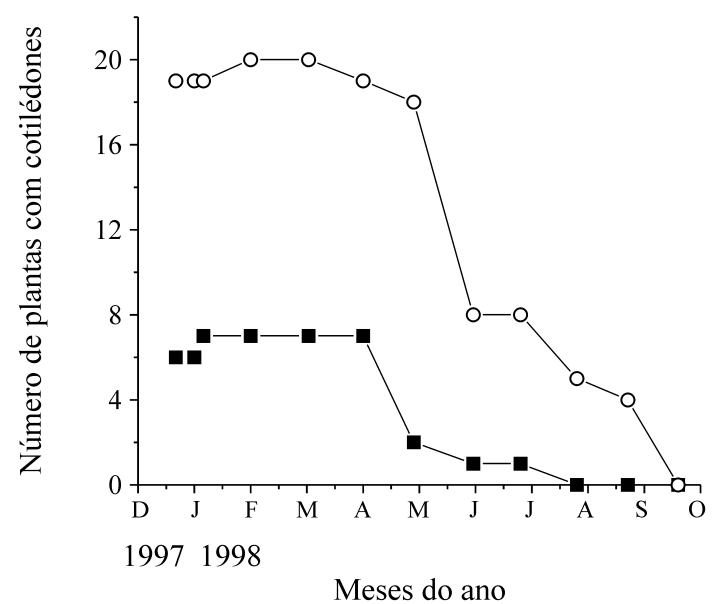

Figura 5. Tempo de duração dos cotilédones de plântulas de $B$. virgilioides no campo sujo e no cerradão. As sementes foram plantadas em 4 de dezembro de 1997. (ロ): cerradão; (O): campo sujo.

ocorreu nos primeiros meses após a emergência das plântulas, ainda na estação chuvosa. A emergência de plântulas foi menor no cerradão e poucas plantas sobreviveram nesta fitofisionomia. Períodos secos de curta duração são freqüentes durante a estação chuvosa na região Centro-Oeste e podem ser prejudiciais para a sobrevivência de plântulas, cujo sistema radicular ainda não está plenamente desenvolvido. Moreira (1992) relatou que os sistemas radiculares de plantas de cinco meses de idade, de dez espécies do cerrado cultivadas em casa de vegetação, não ultrapassaram os $50 \mathrm{~cm}$ de profundidade, indicando que estas espécies estariam expostas ao déficit hídrico nos estágios iniciais de desenvolvimento. Hoffmann (1996) demonstrou que a irrigação durante a estação chuvosa aumentou significativamente a sobrevivência de plântulas de Roupala montana e Miconia albicans, em um cerrado do Distrito Federal. O déficit hídrico que ocorreu na estação seca não influenciou a sobrevivência de $B$. virgiliodes, mas afetou o seu desenvolvimento. $\mathrm{O}$ crescimento da parte aérea foi interrompido e houve uma redução no número de folíolos por planta.

Em ambas fitofisionomias, o sombreamento pode limitar a produtividade de $B$. virgiliodes, nas fases iniciais de desenvolvimento. Os efeitos do sombreamento se tornam especialmente críticos em ambientes florestais como o cerradão, mesmo se considerarmos que, dependendo do potencial de aclimatação desta espécie, um aumento da eficiência fotoquímica do aparato fotossintético poderia minimizar os efeitos do sombreamento. Entretanto, os valores de DFF medidos no cerradão foram superiores aos valores medidos abaixo do dossel ou em pequenas clareiras de florestas tropicais (Osunkoya et al. 1993, Fetcher et al. 1994), provavelmente devido a menor biomassa arbórea do cerradão, quando comparado a florestas tropicais. No campo sujo, a cobertura herbácea apresentou altura máxima de 50 $\mathrm{cm}$ e os valores de DFF mantiveram-se na mesma faixa dos valores medidos abaixo do dossel de gramíneas no deserto de Sonora, Estados Unidos (Franco \& Nobel 1988). Portanto, pequenas mudanças no tamanho da planta podem levar a um rápido aumento na DFF incidente e, consequentemente, no potencial de assimilação de $\mathrm{CO}_{2}$, resultando numa maior oferta de carbono para o crescimento. Entretanto, aumentaria o risco de fotoinibição, especialmente na estação seca (Mattos 1998, Lemos-Filho 2000). Experimentos de sombreamento em casa de vegetação, relataram que plântulas de Vochysia tucanorum e Sclerolobium paniculatum, duas espécies arbóreas do cerrado, apresentaram maior acúmulo de biomassa para a planta inteira, quando expostas a aproximadamente $50 \%$ de sombreamento (Felfili et al. 1999, Barbosa et al. 1999).

Diferenças no estado hídrico e nutricional das plantas poderiam modificar a resposta fotossintética à disponibilidade de luz nas duas fitofisionomias. $\mathrm{O}$ estresse hídrico só seria um fator importante para a assimilação de $\mathrm{CO}_{2}$ de $B$. virgilioides na estação seca, já que o solo nas duas fitofisionomias permaneceu úmido durante a maior parte da estação chuvosa. Entretanto, $\Psi$ s diminuiu consideravelmente durante a estação seca, atingindo $-6,2 \mathrm{MPa}$ a $5 \mathrm{~cm}$ de profundidade e -2,6 MPa a $60 \mathrm{~cm}$ de profundidade, no campo sujo. $\Psi$ s decresceu menos no cerradão, atingindo -2,8 e -1,8 MPa, para estas profundidades. Os valores mais altos de $\Psi$ s no cerradão foram, provavelmente, devido a baixa densidade de gramíneas com raízes superficiais no solo e ao maior sombreamento nesse tipo de ambiente (Sarmiento et al. 1985). Espécies lenhosas do cerrado apresentam uma restrição considerável da abertura estomática e fotossíntese na época seca (Franco 1998, Moraes \& Prado 1998). Mudas de D. miscolobium em 
condições de casa de vegetação, apresentaram valores de condutância estomática próximos de zero, a potenciais hídricos foliares de -1,5 MPa (Sassaki et al. 1997). Experimentos com algumas espécies de plantas lenhosas do cerrado, mostraram que o ponto de compensação fotossintético (taxa de assimilação de $\mathrm{CO}_{2}=$ taxa de respiração) foi alcançado a valores de potencial hídrico foliar entre-3,0 MPa e-4,0 MPa, (Sato Moraes 1992). Portanto, diferenças no estado hídrico do vegetal entre as duas fitofisionomias não devem afetar consideravelmente o balanço de carbono anual de $B$. virgilioides, pois a maior parte do ganho de carbono pela planta deve ocorrer na época chuvosa. Em relação a diferenças nutricionais, não temos dados de concentração foliar de nutrientes, mas os solos desta área são distróficos e diferem pouco entre as duas fitofisionomias (Haridasan 1987).

No campo sujo, cerca de $40 \%$ das plantas mantiveram seus cotilédones por períodos superiores a seis meses. A duração dos cotilédones foi menor no cerradão. É comum às espécies lenhosas do cerrado manterem seus cotilédones por períodos de um ou mais meses (Arasaki \& Felippe 1990, Sassaki \& Felippe 1992) ou até mesmo por mais de um ano (Handro 1969). Estudos com Dalbergia miscolobium, uma leguminosa arbórea típica do cerrado, indicaram que os cotilédones são um importante órgão de reserva, apresentando alto teor de amido, passando a ter função fotossintética após 20 dias de idade (Sassaki Felippe, 1992). Os mesmos autores relataram que a retirada dos cotilédones provocou uma redução acentuada no crescimento de plântulas de D. miscolobium. Portanto, o esgotamento mais rápido das reservas cotiledonares no cerradão é consistente com a maior limitação das taxas fotossintéticas neste ambiente.

Espécies arbóreas do cerrado, durante os estádios iniciais de desenvolvimento, caracterizam-se por um rápido crescimento da raiz, contrastando com um lento crescimento da parte aérea (Handro 1969, Arasaki \& Felippe 1990, Godoy \& Felippe 1992). Assim sendo, além do sombreamento e déficit hídrico sazonal, o crescimento lento da parte aérea pode ser também resultado de um maior investimento no sistema radicular. A disponibilidade de luz pode afetar a repartição de biomassa pela planta. Plântulas de V. tucanorum e S. paniculatum apresen- taram menor razão raiz/parte aérea nas condições de 90-95\% de sombreamento, em experimentos realizados em casa de vegetação, sob diferentes níveis de sombreamento (Felfili et al. 1999, Barbosa et al. 1999).

Em síntese, B. virgilioides demonstrou capacidade de colonizar ambientes mais abertos, apesar do sombreamento pelo estrato herbáceo e possível competição por água e nutrientes resultarem em um crescimento lento da parte aérea. Resultados semelhantes foram relatados para duas outras espécies arbóreas típicas do cerrado, $K$. coriacea (Nardoto et al. 1998) e D. miscolobium (Franco et al. 1996b). Por outro lado, um ambiente florestal, como o cerradão, não foi propício para o estabelecimento dessa espécie.

Agradecimentos - O presente estudo foi financiado pelo CNPq e pelo PRONEX. Somos gratos à Reserva Ecológica do IBGE, Brasília, por ter fornecido os dados de precipitação e à Fazenda Água Limpa pelo apoio logístico. Ao Prof. Raimundo P.B. Henriques, pelos comentários e orientação nas análises estatísticas. Inésio A.M. Correa montou o sistema de medição de luz.

\section{Referências bibliográficas}

ARASAKI, F.R. \& FELIPPE, G.M. 1990. Crescimento inicial de Kielmeyera coriacea. Ciência e Cultura 42:715-720.

BARBOSA, A.R., YAMAMOTO, K. \& VALIO, I.F.M. 1999. Effect of light and temperature on germination and early growth of Vochysia tucanorum Mart., Vochysiaceae, in cerrado and forest soil under different radiation levels. Revista Brasileira de Botânica 22:275-280.

FELFILI, J.M., HILGBERT, L.F., FRANCO, A.C., SOUZA-SILVA, J.C., RESENDE, A.V. \& NOGUEIRA, M.V.P. 1999. Comportamento de plântulas de Sclerolobium paniculatum Vog. var. rubiginosum (Tul.) Benth. sob diferentes níveis de sombreamento, em viveiro. Revista Brasileira de Botânica 22:297-301.

FETCHER, N., OBERBAUER, S.H. \& CHAZDON, R.L. 1994. Physiological ecology of plants. In La Selva: ecology and natural history of a neotropical rainforest (L.A. McDade, K.S. Bawa, H.A. Hespenheide \& G.S. Hartshorn, eds.). The University Chicago Press, Chicago, p.128-141.

FRANCO, A.C. 1998. Seasonal patterns of gas exchange, water relations and growth of Roupala montana, an evergreen savanna species. Plant Ecology 136:69-76.

FRANCO, A.C., NARDOTO, G.B. \& SOUZA, M.P. 1996a. Patterns of soil water potential and seedling survival in the cerrados of central Brazil. In Anais do VIII Simpósio sobre o Cerrado. EMBRAPA/CPAC, Brasília, p.277-280.

FRANCO, A.C. \& NOBEL, P.S. 1988. Interactions between seedlings of Agave deserti and the nurse plant Hilaria rigida. Ecology 69:1731-1740. 
FRANCO, A.C., SOUZA, M.P.\& NARDOTO, G.B. 1996b. Estabelecimento e crescimento de Dalbergia miscolobium Benth. em áreas de campo sujo e cerrado no D.F. In Impactos de queimadas em áreas de cerrado e restinga (H.S. Miranda, C.H. Saito \& B.F.S. Dias, org.). Departamento de Ecologia, Universidade de Brasília, p.84-92.

GODOY, S.M.A. de \& FELIPPE, G.M. 1992. Qualea cordata: a semente e sua germinação. Revista Brasileira de Botânica 15:17-21.

HANDRO, W. 1969. Contribuição ao estudo da unidade de dispersão e da plântula de Andira humilis Mart. Ex Benth. (Leguminosae-Lotoideae). Boletim Faculdade de Filosofia Ciências e Letras da Universidade de São Paulo 347, Botânica 27:1-189.

HARIDASAN, M. 1987. Distribution and mineral nutrition of aluminium-accumulating species in different plant communities of the cerrado region of Central Brazil. In La capacidad bioproductiva de sabanas (J.J. San José \& R. Montes, eds.). UNESCO/CIET, Caracas, p.309-348.

HOFFMANN, W.A. 1996. The effects of fire and cover on seedling establishment in a neotropical savanna. Journal of Ecology 84:383-393.

JACKSON, P.C., MEINZER, F.C., BUSTAMANTE, M., GOLDSTEIN, G., FRANCO, A., RUNDEL, P.W., CALDAS, L., IGLER, E. \& CAUSIN, F. 1999. Partitioning of soil water among tree species in a Brazilian Cerrado ecosystem. Tree Physiology 19:717-724.

LABOURIAU, L.G., VÁLIO, I.F.M., SALGADO-LABOURIAU, M.L. \& HANDRO, W. 1963. Nota sôbre a germinação de sementes de plantas de cerrados em condições naturais. Revista Brasileira de Biologia 23:227-237.

LEMOS-FILHO, J.P. 2000. Fotoinibição em três espécies do cerrado (Annona crassifolia, Eugenia dysenterica e Campomanesia adamantium) na estação seca e na chuvosa. Revista Brasileira de Botânica 23:45-50.

MATTOS, E.A. 1998. Perspectives in comparative ecophysiology of some Brazilian vegetation types: leaf $\mathrm{CO}_{2}$ and $\mathrm{H}_{2} \mathrm{O}$ exchange, chlorophyll a fluorescence and carbon isotope discrimination. In Ecophysiological strategies of xerophytic and amphibious plants in the Neotropics (F.R. Scarano \& A.C. Franco, eds.). Series Oecologia Brasiliensis, v.4. p.1-22.

MEDINA, E. \& SILVA, J.F. 1990. Savannas of northern South America: a steady-state regulated by water-fire interactions on a background of low nutrient availability. Journal of Biogeography 17:403-413.

MORAES, J.A.P.V. \& PRADO, C.H.B.A. 1998. Photosynthesis and water relations in cerrado vegetation. In Ecophysiological strategies of xerophytic and amphibious plants in the neotropics (F.R. Scarano \& A.C. Franco, eds.). Series Oecologia Brasiliensis v.4. p.45-63.
MOREIRA, A.G. 1992. Fire protection and vegetation dynamics in the Brazilian cerrado. Tese de Doutorado, Havard University, Massachusetts.

NARDOTO, G.B., SOUZA, M.P. \& FRANCO, A.C. 1998. Estabelecimento e padrões sazonais de produtividade de Kielmeyera coriacea (Spr) Mart. nos cerrados do Planalto Central: efeitos do estresse hídrico e sombreamento. Revista Brasileira de Botânica 21:313-319.

OSUNKOYA; O.O., ASH, J.E., GRAHAM, A.W., \& HOPKINS, M.S. 1993. Growth of tree seedlings in tropical rain forests of North Queensland, Australia. Journal of Tropical Ecology 9:1-18.

PRADO, C.H.B.A. 1994. Capacidade fotossintética de algumas espécies lenhosas do cerrado sob condições de campo. Tese de doutorado, Universidade Federal de São Carlos, São Carlos.

PRADO, C.H.B.A. \& MORAES, J.A.P.V. de 1997. Photosynthetic capacity and specific leaf mass in twenty woody species of Cerrado vegetation under field conditions. Photosynthetica 33:103-112.

RATTER, J.A., BRIDGEWATER, S., ATKINSON, R. \& RIBEIRO, J.F. 1996. Analysis of the floristic composition of the Brazilian cerrado vegetation II: comparison of the woody vegetation of 98 areas. Edinburgh Journal of Botany 53:153-180.

RAWITSCHER, F. 1948. The water economy of the vegetation of the 'Campos Cerrados' in southern Brazil. Journal of Ecology 36:237-268.

RIBEIRO, J.F. \& WALTER, B.M.T. 1998. Fitofisionomias do bioma Cerrado. In Cerrado Ambiente e Flora (S.M. Sano, \& S.P. de Almeida, eds.). EMBRAPA/CPAC, Planaltina, D.F., p.89-186.

RIZZINI, C.T. 1965. Experimental studies on seedling development of cerrado woody plants. Annals of the Missouri Botanical Garden 52:410-426.

SARMIENTO, G. 1984. The ecology of neotropical savannas. Harvard University Press, Cambridge.

SARMIENTO, G., GOLDSTEIN, G., MEINZER, F. 1985. Adaptive strategies of woody species in neotropical savannas. Biological Reviews of the Cambridge Philosophical Society 60:315-355.

SASSAKI, R.M. \& FELIPPE, G.M. 1992. Remoção dos cotilédones e desenvolvimento inicial de Dalbergia miscolobium. Revista Brasileira de Botânica 15:5-16.

SASSAKI, R.M., MACHADO, E.C., LAGÔA, A.M.M.A. \& FELIPPE, G.M. 1997. Effect of water deficiency on photosynthesis of Dalbergia miscolobium Benth., a cerrado tree species. Revista Brasileira de Fisiologia Vegetal 9:83-87.

SATO, A. MORAES, J.A.P.V. 1992. O efeito do estresse hídrico sobre as trocas do $\mathrm{CO}$ gasoso em plantas jovens de espécies do cerrado. Arquivos de Biologia e Tecnologia 35:763-775. 